\title{
Manufacturing Light Concrete with PET Aggregate
}

\author{
Francisco Casanova-del-Angel ${ }^{1}$ and Jorge Luis Vázquez-Ruiz ${ }^{2}$ \\ ${ }^{1}$ Department of Structural Engineering, SEPI de la ESIA, Unidad Prof. ALM, IPN, 07738 Mexico City, DF, Mexico \\ ${ }^{2}$ Civil Engineering Division, UJA de Tabasco, 86040 Villahermosa, TAB, Mexico
}

Correspondence should be addressed to Francisco Casanova-del-Angel, fcasanova@ipn.mx

Received 20 June 2012; Accepted 3 September 2012

Academic Editors: I. Raftoyiannis and E. J. Sapountzakis

Copyright ( 2012 F. Casanova-del-Angel and J. L. Vázquez-Ruiz. This is an open access article distributed under the Creative Commons Attribution License, which permits unrestricted use, distribution, and reproduction in any medium, provided the original work is properly cited.

\begin{abstract}
The manufacture of concrete using a polymer instead of a stony coarse aggregate known as gravel is presented. Polyethylene terephthalate (PET) is the polymer used, recycling soft drink containers with sufficient tenacity. PET is a material commonly used by engineers as a structural element, not as an aggregate. The research work revealed that PET aggregate produces good quality mixtures with lower volumetric weight but mechanical behavior similar to that of natural concrete with adequate granulometry. The water/cement (W/C) ratio is lower for light concretes than for natural concrete. Regarding stress and Flexural strength, it was found that for $300 \mathrm{~kg} / \mathrm{cm}^{3}$ and higher cement consumption, which may be due to the fact that at low $W / C$ ratios, the coarse aggregate behavior prevails, while at high $W / C$ ratios, the paste behavior prevails. This leads us to the fact that PET aggregate is best applied on low cement consumption up to $300 \mathrm{~kg} / \mathrm{m}^{3}$, since expensive mixtures for higher consumption may result from use on higher consumption. Modulus of elasticity for light concretes is lower than for natural concretes. Deformations are lower for light concretes than for natural concretes. A feature of using PET to substitute coarse aggregate is volumetric weight, since it is $68.88 \%$ lighter than concrete with natural aggregates.
\end{abstract}

\section{Introduction}

Throughout history, plastics may have been considered a major technical breakthrough in the XX Century, mainly due to the fact that they have preceded new inventions and have substituted other materials in already existing products. They are light, durable, and versatile, as well as resistant to humidity, chemical products, and degradation. However, such properties constitute a challenge for solid and dangerous waste agents.

Plastics recycling around the world has increased considerably due to the need to solve the problem of accumulation of solid urban waste, which has promoted developing alternative recycling systems and assessing the value of waste, particularly nonreturnable containers. By means of the combined use of concrete and polyethylene terephthalate (PET) in building, a technology scarcely studied in Mexico is being projected. There exists research leading us to consider PET as an aggregate and not as substitute in the mixture [1].

International research regarding the use of PET as an aggregate already shows some progress worth considering. There exists a research on the surface microstructure of PET waste from plastic bottles used as a lightweight aggregate to examine the effect of granulated blast-furnace slag [2]. PET has also been used as a partial and whole substitute of sand in concrete composites. Various fractions in sand volume with $2 \%-100 \%$ variations were substituted by the same volume of plastic granulates, using various PET aggregate sizes. In order to study the relationship between the mechanical properties and the compound microstructure, the electron microscope and analysis technique were used.

Results show that substituting sand with volume below $50 \%$ with granulate PET, with a $5 \mathrm{~mm}$ higher granular limit, affects its compression strength, as well as the flexural stress of compound materials. The study shows that stripped plastic bottles may be properly used as sand aggregate substitute in concrete [3]. Strength and resistance to acid and alkaline compounds of concrete have been measured, varying the total content of coarse and fine resins ratio, thus obtaining that the strength of the polymer made from a PETbased resin increases as the resin content is higher; however, beyond a certain resin content, the strength does not vary in a significant manner. The stress-strain curves of polymer concretes with $100 \%$ natural aggregate and $100 \%$ recycled 
aggregate showed different failure mechanisms of the compressed materials [4]. The mechanical behavior of concrete with recycled PET varying the water/cement ratio (0.50 and $0.60)$, and the particle size ( $10 \%$ y $20 \%$ volume), was also studied [5].

The conclusion regarding advantages of the use of recycled PET in the production of polymer concrete is that PET's waste does not have to be purified, including removal of colors to the extent that other PET recycling applications might require (coats, pillows, carpets, etc.), which minimizes the cost of resin based on recycled PET. Polymerization process of styrene supported on recycled resin polyesters is confirmed by micrographs with the scanning electron microscope, which polymer mortar matrix shows that it has a very low porosity in comparison to the cement mortar of even rich grade. The X-ray diffraction pattern of hardened polymer mortar composite material for different sets indicates the crystalline nature of the material due to the presence of aggregate (coarse sand), whereas the nature of hardened polymer resin is amorphous [6]. Rheological characterization on fresh concrete and mechanical tests at 28 and 365 days were performed on reference concretes, containing only natural fine aggregate in order to investigate the influence of the substitution of PET washed bottles in the fine aggregate in concrete. Concretes displayed similar workability features, compressive strength, and splitting tensile strength slightly lower than the reference concrete, and a moderately higher ductility [7]. Besides, research has been carried out on the use of PET as a lightweight aggregate in mortar, one made with only PET aggregates and second made with PET and sand aggregates together. Additionally, blast-furnace slag was also used as the replacement of cement on mass basis at a $50 \%$ replacement ratio to reduce the amount of cement used and provide savings [8].

Recycling implies reprocessing materials, in this case, PET, in order to condition them with the purpose to integrate such again into a productive cycle as raw material. There are three main ways to take advantage of PET containers once their useful life has ended: to subject those to mechanical, chemical, or energetic recycling, the latter in order for such to be used as a source of energy. Mechanical recycling is the process used most of the times, consisting in several separations, cleaning, and crushing stages. For chemical recycling, various processes have been developed. Methanolysis and glycolysis are carried out at an industrial scale. PET is melt or polymerized, its molecules are separated and used to manufacture PET once more. Depending on its purity, this material may even be used to pack food. While energetic recycling has the premise to use PET as an alternate fuel, containers may be used to generate energy, since such material has a $6.3 \mathrm{Kcal} / \mathrm{Kg}$ heating power and may carry out an efficient combustion. This is possible since neither additives or modifiers are used in their manufacture, which enables nontoxic combustion effluence, only obtaining carbon dioxide and water vapor [9]. Regarding recycling, using plastics reduces the mass of materials required in a wide variety of applications and sectors. The more numerous, specialized, technologized, and differentiated are plastic materials, the harder is to recover such. There are a lot of documents on their classification, treatment, management and recycling. In Mexico, two of the first written documents on this subject were: "Dangerous Waste in the World and Mexico" [10] and "Recycling and Management of Containers and Packing Waste" [11].

Our research proposes recycling PET as a coarse aggregate in order to offer a solution to the accumulation of hazardous waste. Feasibility of the proposal is demonstrated by an assessment of mechanical properties of concrete made from nonstony coarse aggregates produced from recycling nonreturnable containers, compared, under the same manufacturing conditions, to the properties of concrete with natural aggregates (made from natural aggregates). Mechanical properties compared including the modulus of elasticity, as well as compression, tensile and flexural strength, obtained from laboratory tests. Experimental results showed that recycled PET aggregates produce concretes that may be used as Class II concretes, in accordance with the Building Rules and Regulations for the Federal District. These results show that it is feasible to recycle PET as a means to solve the problem of hazardous waste.

\section{Aggregates}

In this research, limestone was used as natural stony aggregate. Coarse aggregates, produced by shredding disposable containers, are called light aggregates. In the case of these aggregates, known as polymers, took care that containers were clean labels and rubber as well as door that leads the bottleneck because it is another kind of polymer tanks, tags contain rubber, tapas are greater mechanical resistance but may have a fragile failure, and this can reduce the resistance of the mixture.

Only natural river sand was used for fine aggregates. A $19 \mathrm{~mm}\left(3 / 4^{\prime \prime}\right)$ maximum aggregate size (MAS) was considered for the light PET aggregate and a granulometric interval for nongraduated material was used, in accordance with ASTM C 33 standard [12].

\section{Experimental Work}

Manufacture of concrete was carried out in three stages: first, collection, cleaning, and crushing; second, dosing materials to prepare mixture (cement, sand, PET, and water); third, mixture preparation.

(i) PET collection was carried out manually, taking care that containers were clean, since most of them still had glued stickers. Stickers and caps were removed, since the material to manufacture caps has a higher mechanical strength, but fragile failure, which may lower the strength of the mixture. Bottles were manually washed with water and soap and dried directly under the sun. Finally, they were crushed with a crushing machine at $19 \mathrm{~mm}\left(3 / 4^{\prime \prime}\right)$ for the purposes of the study.

(ii) Mixtures were then designed, analyzing in the laboratory their specific weight, volumetric weight, and $\mathrm{PET} /$ sand ratio, Figure 1, Table 1. After those analyses 


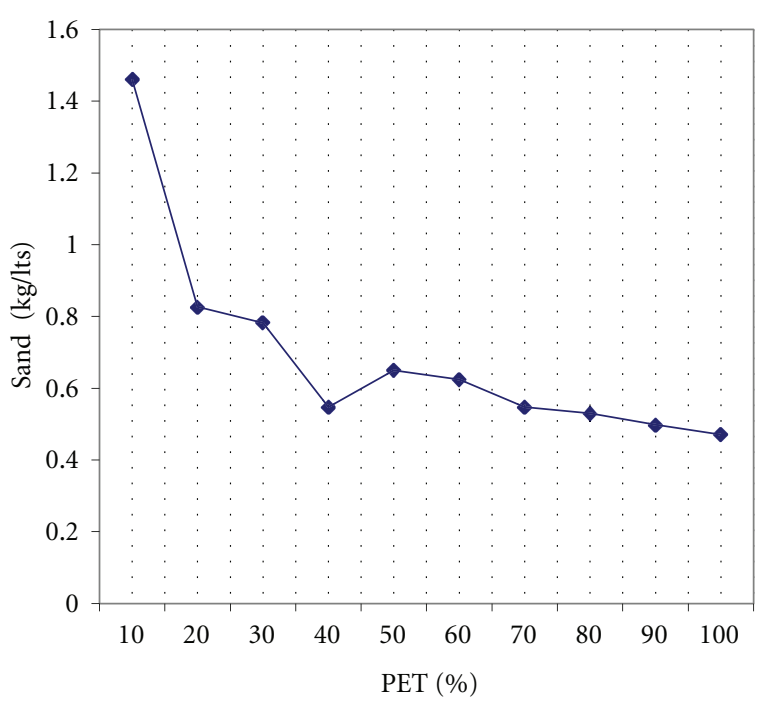

Figure 1: Relation PTE and sand.

were carried out, cement, sand, PET, and water quantities for a cubic meter were obtained, Table 2.

(iii) Using data above, mixtures with each material were prepared, and three cylindrical moulds used to mechanically obtain the mixtures were filled, for each strength in the study, Table 2.

\section{Manufacturing}

The original granulometry of the PET aggregate was outside the limits established by ASTM C 33 ibid standard for the MAS taken into consideration; therefore, the material needed to be crushed in order to meet the standard. Crushing took into account a ratio of $35 \%$ particles passing through the $9.5 \mathrm{~mm}\left(3 / 8^{\prime \prime}\right)$ mesh, which made possible to comply with the standard. The general crushing and manufacturing process of light concrete, LC, using PET as component in concrete, is shown in Figure 1.

Crushing equipment was an electric claw crusher accepting a $76 \mathrm{~mm}\left(3^{\prime \prime}\right)$ MAS. A manual screen with $19 \mathrm{~mm}\left(3 / 4^{\prime \prime}\right)$, $9.5 \mathrm{~mm}\left(3 / 8^{\prime \prime}\right)$, and $4.76 \mathrm{~mm}$ (no. 4) meshes was used to screen the material. Materials were screened: those retained in $19 \mathrm{~mm}\left(3 / 4^{\prime \prime}\right)$ mesh, and three passing through a $19 \mathrm{~mm}$ $\left(3 / 4^{\prime \prime}\right)$ mesh, a $9.5 \mathrm{~mm}\left(3 / 8^{\prime \prime}\right)$ mesh, and a $4.76 \mathrm{~mm}$ (no. 4$)$ mesh. Sizes used for the granulometry were those passing through $19 \mathrm{~mm}\left(3 / 4^{\prime \prime}\right)$ and $9.5 \mathrm{~mm}\left(3 / 8^{\prime \prime}\right)$.

Light PET-derivative aggregates were manufactured in accordance with the crushing and screening procedure used for natural aggregates, Figure 2, the only difference being that nonreturnable containers were used as raw material. The material under analysis was cleaned to be followed by primary manual shredding and the manufacturing process, Figure 2.

\section{Standards Used}

The results of natural aggregates and light PET aggregates are shown together for comparison purposes. The physical properties of fine aggregates studied were: granulometry, modulus of fineness, humidity, absorption, relative density, and compacted volumetric weight.

Granulometry of natural coarse aggregates and PET was controlled in accordance with the standard, in order to establish the same conditions and a basis for comparison. Figure 3 shows the granulometric curves of the two types of coarse aggregates. A granulometric correction was not made for the fine aggregate, since it was considered that its granulometry was sufficient to be used in concrete mixtures, in accordance with the ASTM C-125-07 [13] standards. Figure 4 shows the granulometric curve of sand used in the two tests, for both light concrete, LC, and natural concrete, NC. The modulus of fineness (MF) of the sand was obtained in accordance with the standard. With a 2.37 value, it shows that sand is coarse, in accordance with the aforementioned standards.

Shape coefficient was calculated in accordance with the French standard AFNOR P-18301 [14] defining the shape of gravel. Table 1 shows the results of natural coarse aggregate (gravel) and substitute PET, shape coefficients, where it may be observed that such vary slightly, based on which it may be assumed that they are similar. This was to be expected, since both materials were crushed under the same specifications. The shape of both aggregates' particles complies with the limits specified by this standard, a minimum of 0.15 . In order to characterize the aggregate's shape, the standard defines a volumetric coefficient equal to the relationship between the volume $v$ of the aggregate, in $\mathrm{mm}^{3}$, and the volume of the diameter sphere $n$ in millimeters, $n$ being the largest dimension of the diameter of this element. Humidity of every aggregate (natural, PET, and sand) when the experiments were carried out was measured following the procedure established in the ASTM C-566-89 [15] standard. Values obtained, shown in Table 1, clearly show that humidity of coarse PET aggregate is lower than that of natural aggregates, values which were used to dose the concrete mixtures, since variations on such were anticipated. Absorption was measured in accordance with ASTM C-12788 [16] and ASTM C-128-88 [17] standards for coarse and fine aggregates, respectively. The results, Table 1 , show that coarse PET aggregate is not more absorbent than natural aggregates; however, both of them, as well as sand, are within normal ranges. Table 1 shows that density of PET aggregate was lower than that of natural aggregates. This was to be expected, as the content of cement paste in PET material decreases the overall density of the aggregate. The normal relative density interval for most natural aggregates goes from 2.4 through 2.90 [18]. Therefore, PET aggregate has a low relative density compared to that of a natural aggregate. The value measured in the laboratory $(0.130)$ is not very close to the variation range of natural aggregates, although it is acceptable. Finally, compacted volumetric weight of an aggregate used for normal-weight concrete ranges from $1200 \mathrm{~kg} / \mathrm{m}^{3}$ through $1760 \mathrm{~kg} / \mathrm{m}^{3}$. The values obtained in the laboratory are within this range for natural aggregates and outside for light concrete, Table 1. 
TABLE 1: Results of physical properties.

\begin{tabular}{lccccc}
\hline Aggregate & Shape coefficient & Humidity $(\%)$ & Absorption $(\%)$ & Density $(\%)$ & Vol. weight $\left(\mathrm{kg} / \mathrm{m}^{3}\right)$ \\
\hline Natural & 0.200 & 0.040 & 0.420 & 2.710 & 1563 \\
PET & 0.707 & 0.000 & 0.000 & 0.130 & 760 \\
Sand & - & 6.930 & 1.010 & 2.630 & 1584 \\
\hline
\end{tabular}

TABLE 2: Values obtained in each test samples.

\begin{tabular}{|c|c|c|c|c|c|c|c|c|}
\hline Aggregate $\left(\mathrm{kg} / \mathrm{cm}^{2}\right)$ & $\mathrm{CN}-150$ & $\mathrm{CN}-200$ & $\mathrm{CN}-250$ & $\mathrm{CN}-300$ & CL-150 & CL-200 & CL-250 & CL-300 \\
\hline Water $\left(\mathrm{kg} / \mathrm{cm}^{2}\right)$ & 205 & 205 & 205 & 205 & 225 & 225 & 225 & 225 \\
\hline Cement $\left(\mathrm{kg} / \mathrm{m}^{3}\right)$ & 310 & 350 & 390 & 450 & 281 & 321 & 365 & 409 \\
\hline Gravel/PET $\left(\mathrm{kg} / \mathrm{m}^{3}\right)$ & 1000 & 1000 & 1000 & 1000 & 133 & 133 & 133 & 133 \\
\hline Sand $\left(\mathrm{kg} / \mathrm{m}^{3}\right)$ & 860 & 825 & 790 & 740 & 716 & 698 & 678 & 657 \\
\hline Shrinkage $(\mathrm{cm})$ & 8.7 & 9.7 & 9.8 & 10.0 & 8.6 & 9.5 & 9.6 & 9.7 \\
\hline Fresh volumetric weight $\left(\mathrm{kg} / \mathrm{m}^{3}\right)$ & 1563 & 2246 & 2190 & 2100 & 1360 & 1385 & 1403 & 1431 \\
\hline Air content $(\%)$ & 2 & 2 & 2 & 2 & 1.6 & 1.7 & 1.8 & 1.9 \\
\hline$W / C$ ratio & 1.3 & 1.01 & 0.82 & 0.47 & 0.8 & 0.7 & 0.62 & 0.55 \\
\hline Compression strength $\left(\mathrm{kg} / \mathrm{cm}^{2}\right) 7$ days & 145.7 & 116.7 & 192.3 & 218.2 & 143.5 & 160.57 & 193.41 & 250.18 \\
\hline Compression strength $\left(\mathrm{kg} / \mathrm{cm}^{2}\right) 14$ days & 149.3 & 145.08 & 199.25 & 252.25 & 147.41 & 158.38 & 214.84 & 247.97 \\
\hline Compression strength $\left(\mathrm{kg} / \mathrm{cm}^{2}\right) 28$ days & 149.9 & 188.2 & 243.3 & 306.86 & 148.38 & 185.16 & 231.2 & 297.08 \\
\hline Tensile strength $\left(f_{t}\right)\left(\mathrm{kg} / \mathrm{cm}^{2}\right)$ & 18.38 & 21.3 & 23.7 & 24.65 & 14.38 & 16.8 & 18.17 & 20.16 \\
\hline Class I concrete $1.5 *\left(f_{\mathrm{c}}^{\prime}\right)^{1 / 2}$ & 18.37 & 21.21 & 23.72 & 25.98 & 18.27 & 20.41 & 22.81 & 25.85 \\
\hline Class II concrete $1.2 *\left(f_{\mathrm{c}}^{\prime}\right)^{1 / 2}$ & 14.7 & 16.97 & 18.97 & 20.78 & 14.62 & 16.33 & 18.25 & 20.68 \\
\hline Flexural strength $M_{R}\left(\mathrm{~kg} / \mathrm{cm}^{2}\right)$ & 25 & 28.81 & 32.12 & 35.56 & 23.43 & 26.39 & 27.11 & 28.34 \\
\hline Class I concrete $2.0 *\left(f_{\mathrm{c}}^{\prime}\right)^{1 / 2}$ & 24.49 & 28.28 & 31.62 & 34.64 & 24.33 & 27.21 & 30.41 & 34.47 \\
\hline Class II concrete $1.4 *\left(f_{\mathrm{c}}^{\prime}\right)^{1 / 2}$ & 17.15 & 19.8 & 21.14 & 24.25 & 17.03 & 19.05 & 21.29 & 24.13 \\
\hline Modulus of elasticity $E * 10^{3}\left(\mathrm{~kg} / \mathrm{cm}^{2}\right)$ & 155 & 227 & 198 & 263 & 59 & 69 & 86 & 97 \\
\hline Class I concrete $14.000 *\left(f_{\mathrm{c}}^{\prime}\right)^{1 / 2}$ & 172 & 198 & 221 & 243 & 170 & 191 & 213 & 241 \\
\hline Class II concrete $8.000 *\left(f_{\mathrm{c}}^{\prime}\right)^{1 / 2}$ & 98 & 113 & 127 & 139 & 97 & 109 & 122 & 138 \\
\hline
\end{tabular}

\section{Concrete Manufacture}

Natural river sand, with the physical properties described above, was used for both types of concrete, those made from natural aggregates, and those made from PET.

A modified procedure based on ACI-211.1-89 [19, 20] was used to manufacture concrete mixtures, as follows: (i) water consumption was established; (ii) the water/cement ratio was calculated $(W / C)$ in order to determine the cement consumption for each design mixture, namely, $150 \mathrm{~kg} / \mathrm{cm}^{2}$, $200 \mathrm{~kg} / \mathrm{cm}^{2}, 250 \mathrm{~kg} / \mathrm{cm}^{2}$, and $300 \mathrm{~kg} / \mathrm{cm}^{2}$; (iii) the amount of coarse aggregate under analysis (PET) was determined, and (iv) amounts of fine aggregate (sand) were determined for both types of concrete.

The water consumption established by the ACI method was found, based on the MAS considered and the shrinkage established for all mixtures at $10 \mathrm{~cm}$. Then, the absolute volumes for coarse and fine aggregates were defined in percentage terms, which were considered consistent for each use of cement, since the volume of water established in the ACI method is the same for all mixtures and depends on the modulus of fineness (MF) and the volume of coarse, dry, and compact aggregates. Mixtures dosing procedure took previous data obtained in the laboratory, that is, the number of mixtures or tests, $N$, specific weight of cement, $\rho_{c_{e}}$, specific weight of sand $\rho_{A r}$, specific weight of PET, $\rho_{\text {PET }}$, specific weight of water $\rho_{A}$, specific weight of air, $\rho_{\text {air }}$, volumetric weight of PET, $\gamma_{\mathrm{PET}}$, and providing the analysis data for the test such as compression strength of concrete, in $\mathrm{kg} / \mathrm{cm}^{2}, f_{c}^{\prime}$, age or wrought time, in days, $E$, shrinkage of the mixture under analysis, in $\mathrm{cm}, R$, maximum size of a dimensional coarse aggregate, TMA, weight or quantity of water added to the mixture under analysis, in $\mathrm{kg}, A$, water/cement ratio in the dimensional mixture, $R_{A / C_{e}}$, volume of PET, in $\mathrm{m}^{3}, V_{\mathrm{PET}}$, weight of air added to the mixture, in $\mathrm{kg}, A_{\text {air }}$, amount of dosed cement in the mixture, in $\mathrm{kg}, C_{e}$, amount of sand dosed in the mixture, in $\mathrm{kg}$, dosed PET, in $\mathrm{kg}, G_{\mathrm{PET}}$. The mixtures generated with such ratios were labeled as follows: those made using the natural lime aggregate, CN-150, CN-200, $\mathrm{CN}-250$, and CN-300 kg/ $\mathrm{cm}^{2}$, and those made using the PET aggregate, as CL-150, CL-200, CL250, and CL-300 kg/ $\mathrm{cm}^{2}$, respectively. Table 2 shows quantity of water, cement, PET, and mixture sand used, adjusted to the volumetric weight obtained in the laboratory, since the performance of the mixture, in many cases, was slightly higher than $1 \mathrm{~m}^{3}$. The quantities shown are affected by humidity of the material when it was provided. The diagram in Figure 5 show the dosing of mixtures procedure. 


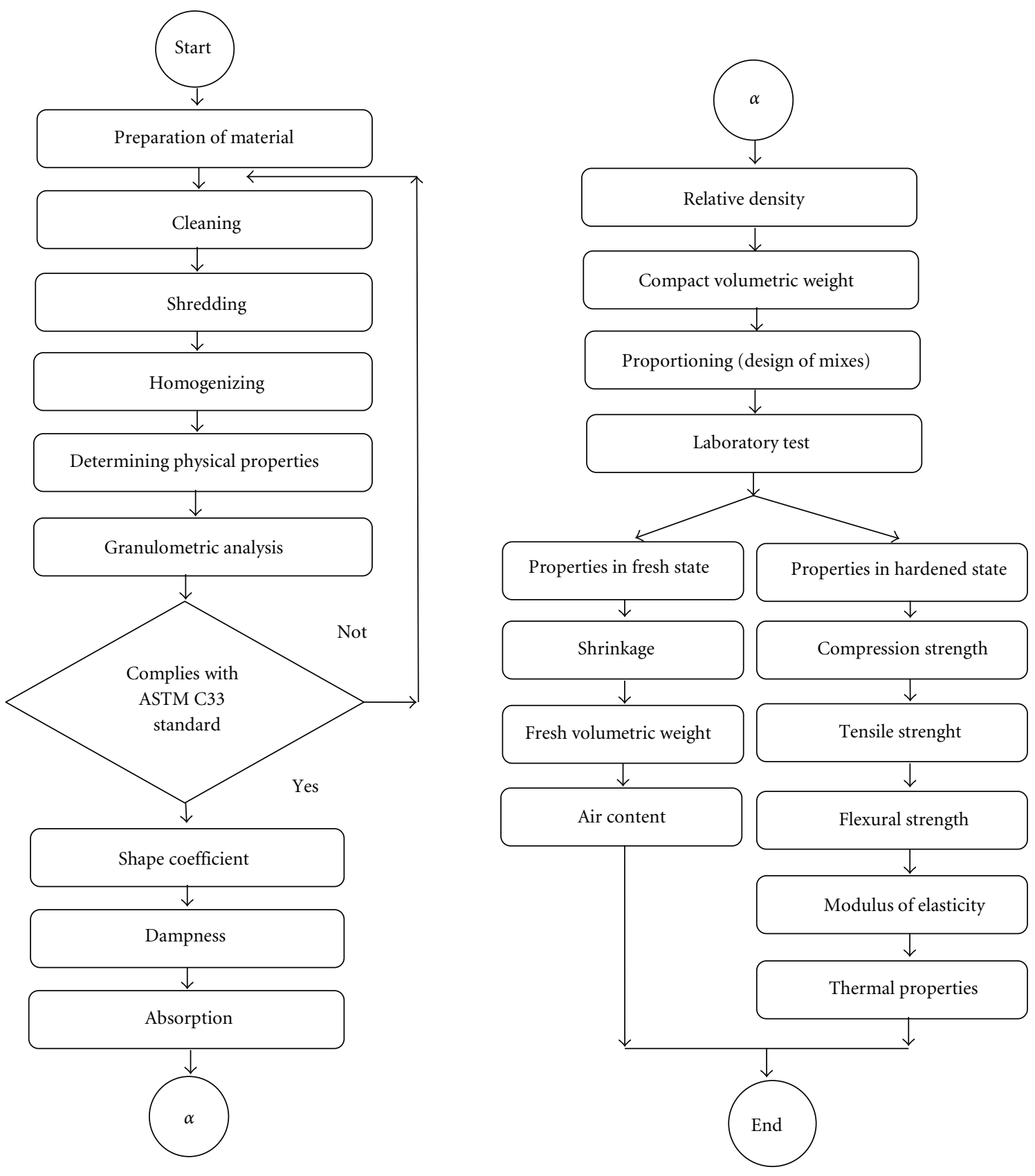

FIgURE 2: General crushing and manufacturing process with PET.

\section{Laboratory Tests}

Laboratory tests on concrete in a fresh state: shrinkage, volumetric weight, and air content and in hardened state: compression, tensile, and flexural stress, as well as the modulus of elasticity, were carried out following the procedures established in the corresponding ASTM standards for each of them. In order to study these properties, cylinders and standard $15 * 30 \mathrm{~cm}$ and $15 * 15 * 60 \mathrm{~cm}$ concrete beams, respectively, were manufactured. Compression, flexural, and tensile strength properties were studied at 7,14 , and 28 days, while the remaining tests were studied only 28 days.
Table 2 shows obtained shrinkage, most shrinkage is within the tolerance limits $( \pm 2.5 \mathrm{~cm})$ established in Section 6.1.2 of ASTM C 94 Standards [21]. Only CN-300 mixture was close to the limit allowed. The results of the research show that consistency of such mixtures with PET is lower than that of natural mixtures [22], (Figure 6).

\section{Fresh Volumetric Weight}

Table 2 shows the fresh volumetric weight and air content results expected and obtained under compression, flexural, and tensile strength, in accordance with the procedure 


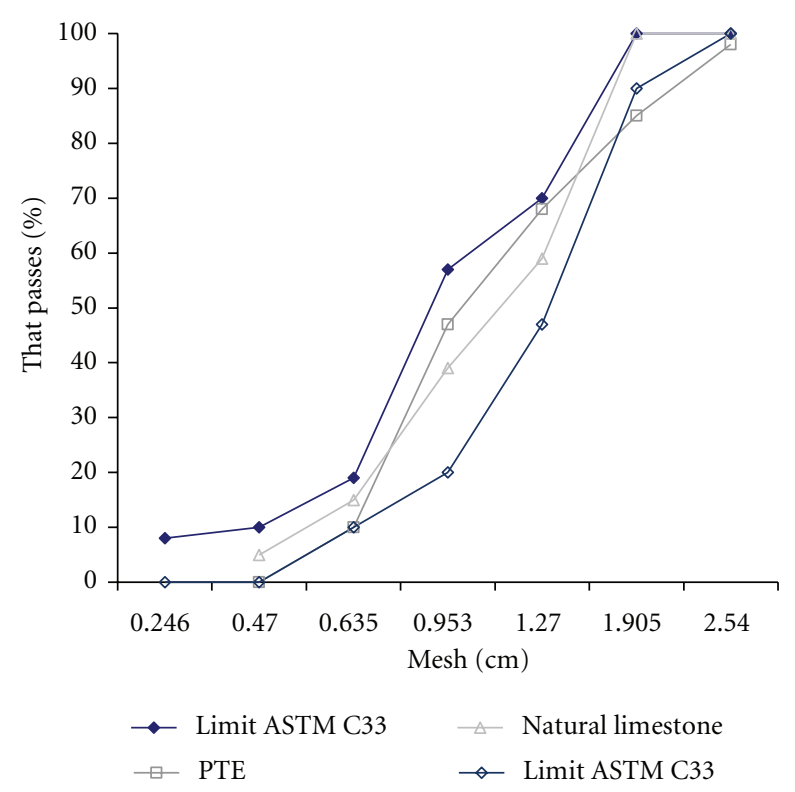

FIGURE 3: Granulometry of the PET aggregate.

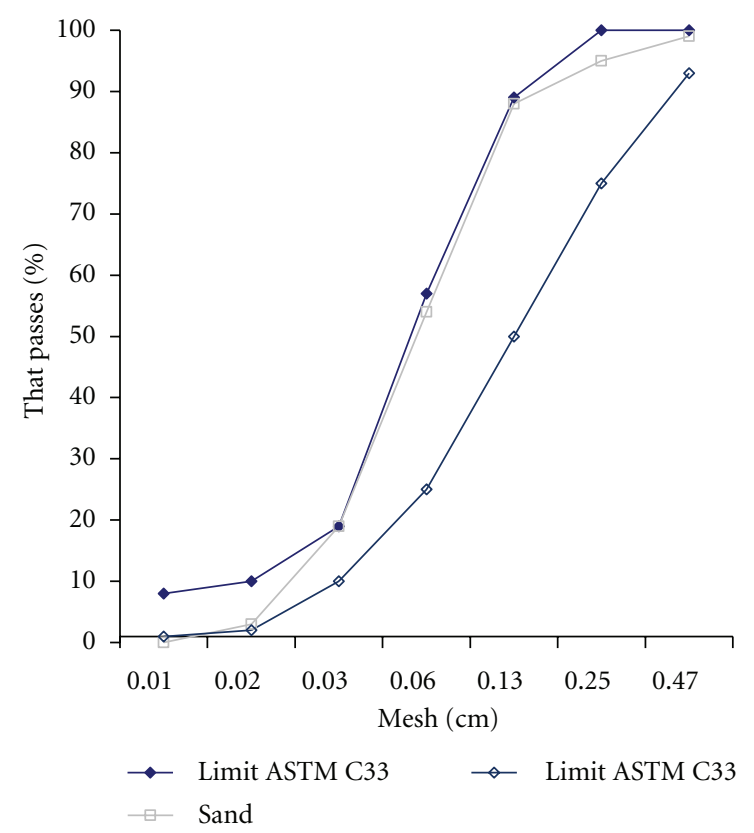

FIGURE 4: Granulometry of the sand aggregate.

established in ASTM C 138 [23] Standards, where the volumetric weight of light concrete was low compared to natural concrete, $i b i d$, this being consistent with the results in this research, where coarse PET aggregate was used.

In accordance with the Building Rules and Regulations for the Federal District, this light concrete is classified as Class II concrete, since its fresh volumetric weight is between $1900 \mathrm{~kg} / \mathrm{m}^{3}$ and $2200 \mathrm{~kg} / \mathrm{m}^{3}$, while natural concrete is classified as Class I, since its fresh volumetric weight is

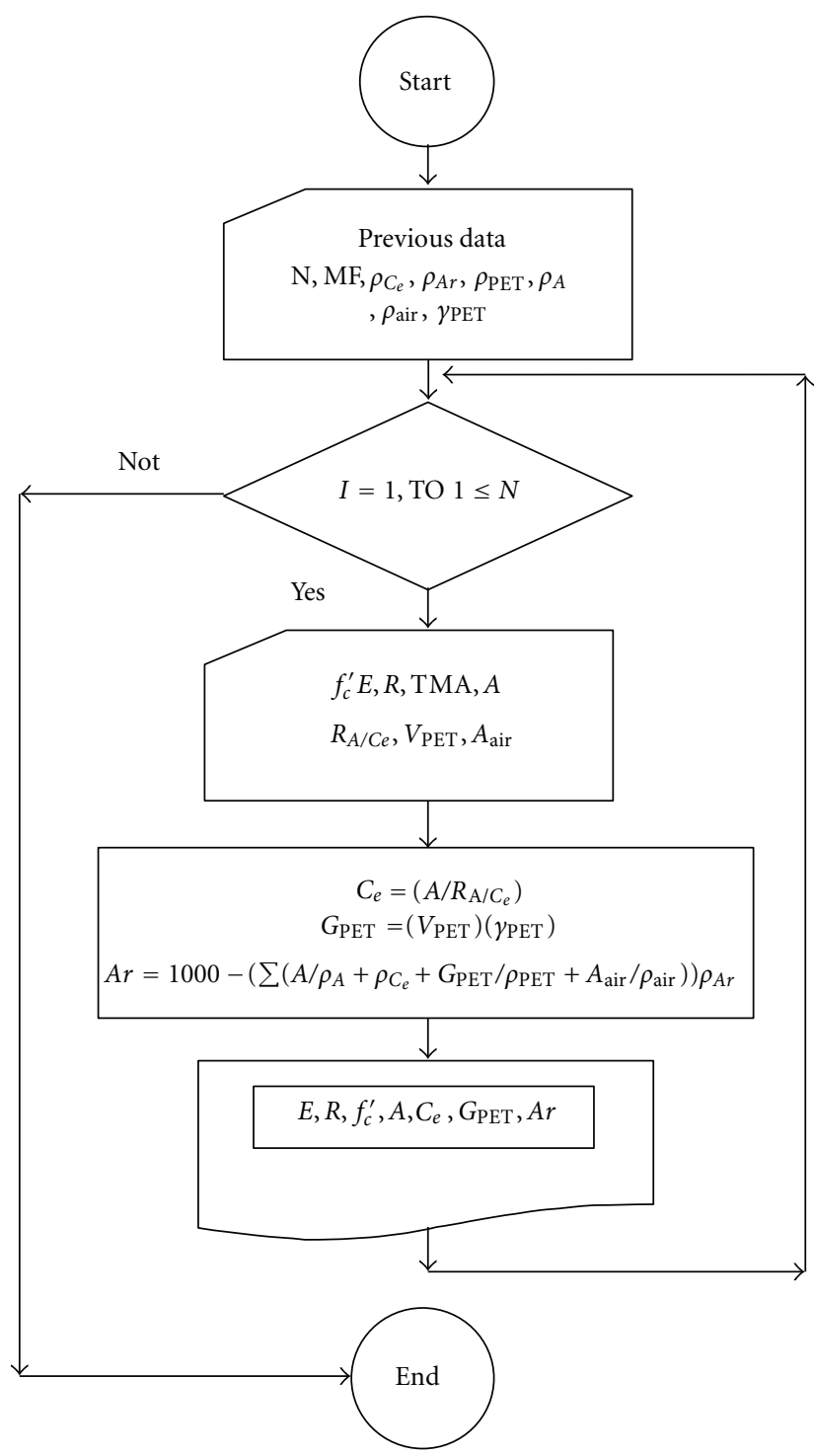

Figure 5: Criteria of dosage of conceret mixtures CL.

higher than $2200 \mathrm{~kg} / \mathrm{m}^{3}$. The air content of concrete mixtures was obtained in accordance with the procedure established in ASTM C 231 Standards [24]. Table 2 shows the air content of the eight mixtures, where it may be observed that the air content of normal mixtures was normal, between 1.5 and $2.0 \%$, which mean value is $1.875 \%$ with a sample deviation of $0.158 \%$.

The average fresh volumetric weight for natural concrete is $2024.75 \mathrm{~kg} / \mathrm{m}^{3}$ with a $313.65 \mathrm{~kg} / \mathrm{m}^{3}$ sample standard deviation, which is $15.5 \%$ of the mean value and a $13.41 \mathrm{~kg} / \mathrm{m}^{3}$ variation coefficient (existing relationship between typical deviation of a sample and its mean value). For light concrete, it is $1394.75 \mathrm{~kg} / \mathrm{m}^{3}$, with a $29.91 \mathrm{~kg} / \mathrm{m}^{3}$ standard deviation, representing $2.14 \%$ of the mean value and a $1.85 \mathrm{~kg} / \mathrm{m}^{3}$ variation coefficient. This means that there is higher consistency in mixtures with light concrete. 


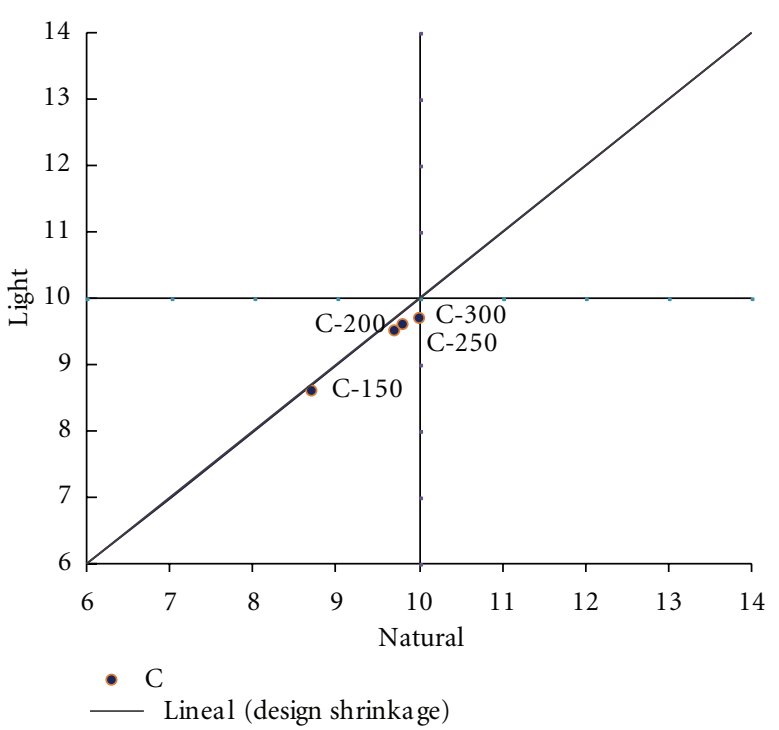

Figure 6: Positioning of shrinkage natural light.

\section{Properties in Hardened Condition}

9.1. Compression Strength. The compression strength was obtained following the procedure established by ASTM C 39 Standard [25]. Obtained compression strengths are shown in Table 2.

The $W / C$ ratios and compression strengths $\left(f_{c}^{\prime}\right)$ at 28 days shown on the graph demonstrate that light concretes have lower strengths than natural concretes for the same $W / C$ ratio, Figure 7 . If the use of cement is related to compression, flexural, and stress obtained, it may be observed that natural concrete is always more efficient than light concrete, even though more cement is used for light concrete, although differences are a few, Figure 8 . Average values of properties in hardened state are: $168.225 \mathrm{~kg} / \mathrm{cm}^{2}$ at 7 days, $186.47 \mathrm{~kg} / \mathrm{cm}^{2}$ at 14 days, and $222.06 \mathrm{~kg} / \mathrm{cm}^{2}$ at 28 days for natural concrete and $186.915 \mathrm{~kg} / \mathrm{cm}^{2}$ at 7 days, $192.15 \mathrm{~kg} / \mathrm{cm}^{2}$ at 14 days, and $215.45 \mathrm{~kg} / \mathrm{cm}^{2}$ at 28 days for light concrete. Variation coefficients are, respectively: $23.47,23.35$, and $26.63 \mathrm{~kg} / \mathrm{cm}^{2}$ for natural concrete and $21.77,21.41$, and $25.76 \mathrm{~kg} / \mathrm{cm}^{2}$ for light concrete. This means that tensile strength varies the most for both mixtures.

9.2. Tensile Strength. Tensile strength $\left(f_{t}\right)$ for a concrete with normal weight is estimated at 1.5 to 1.2 times the square root of compression, flexural and tensile strength for Class I and Class II concrete, respectively. This property was obtained following the procedure established in ASTM C 496 Standard [26]. Table 2 shows the tensile strengths of concrete mixtures, where it may be observed that the tensile strength values of light concrete are slightly lower than those of natural concrete: 79\% for CL-150 and CL-200, 77\% for CL250, and $82 \%$ for CL-300.

When representing the values obtained and established in the Rules and Regulations as trends in a graph, it was observed that PET-based light concretes may be considered

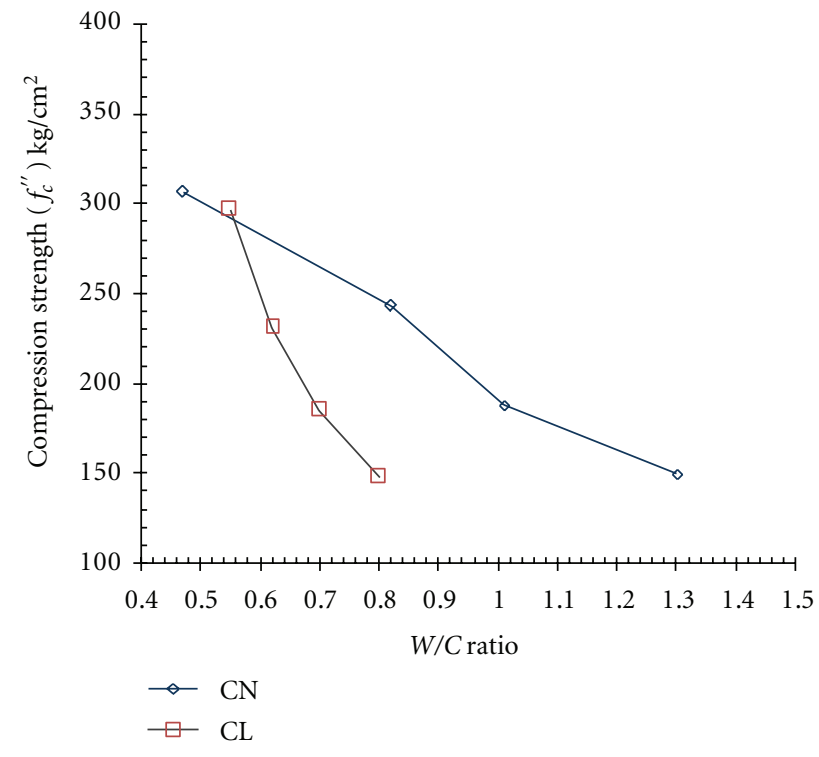

Figure 7: $f_{c}^{\prime}$ Curves Ratio $(W / C)$

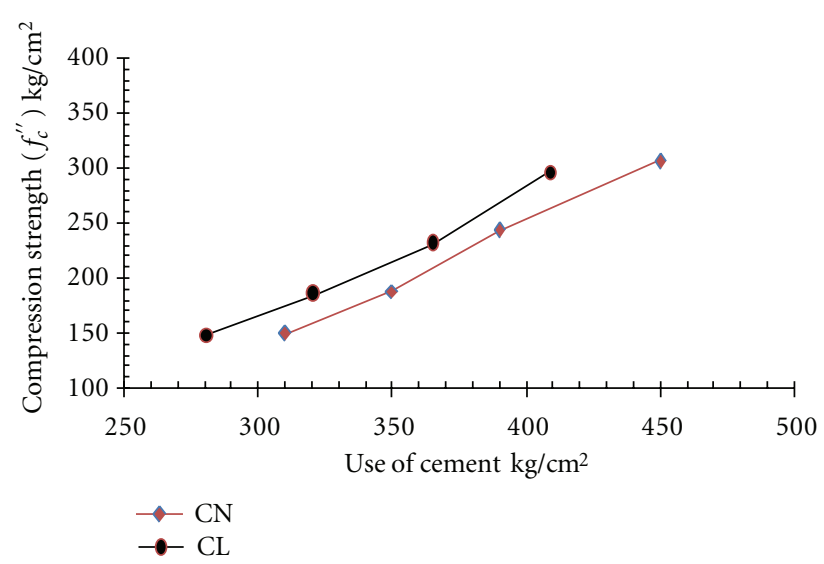

FIgURE 8: Efficiency in the consumption of conceret.

within the classification for Class II concretes, while natural concretes fall within Class I, Figure 9.

9.3. Flexural Strength. Flexural strength, or rupture mode, for concrete of normal weight, is considered as 2 and 1.4 times the square root $f_{c}^{\prime}$ for Class I and II concretes, respectively. The procedure established by ASTM C 78 Standard [27] was followed in order to obtain the flexural strength values of concrete.

Table 2 shows the Flexural strength of concrete studied, where, once more, the values of light concretes were lower than those of natural concretes. The trends of all values of all concrete mixtures studied fall within the classification of concrete, as shown in Figure 10.

\section{Modulus of Elasticity}

It is well known that calculation of the modulus of elasticity of a material is of paramount importance in order to 


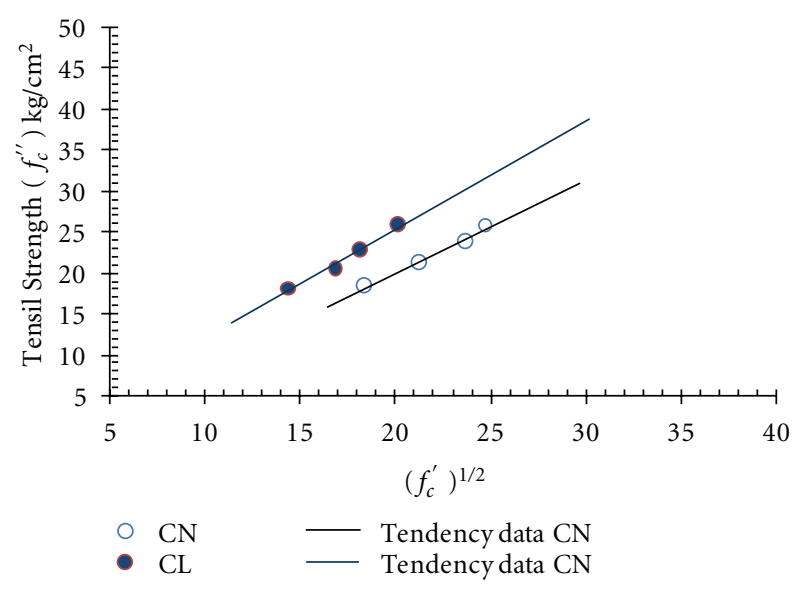

FIGURE 9: Tensile strength.

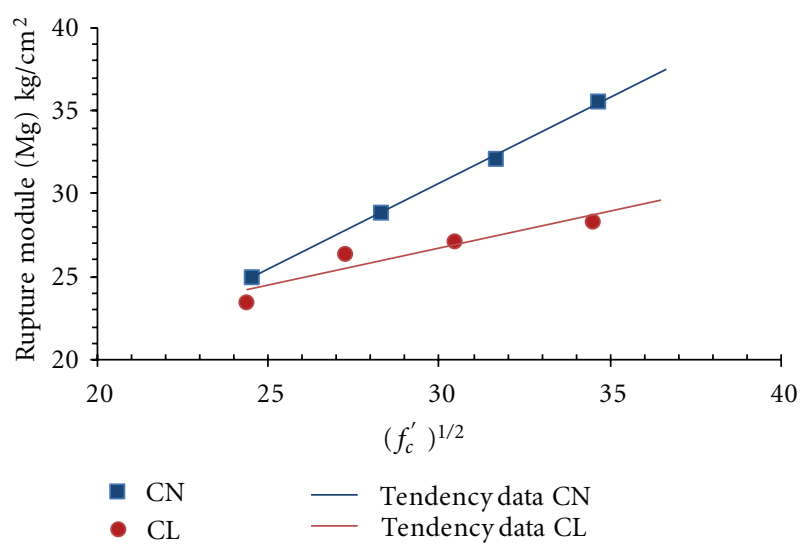

FIGURE 10: Flexural strength of concrete mixtures.

have a good understanding of its mechanical behavior, besides the fact that it is very important for constitutive, plasticity, and/or damage models, as well as to carry out a numerical simulation of its behavior. It relates the stress in accordance with a direction, with deformations produced in such direction.

ASTM C469 Standards [28] were used to obtain the modulus of elasticity of concrete mixtures. In accordance with these standards, the modulus of elasticity may be estimated as 14,000 times the square root and 8,000 times the square root of $f_{c}^{\prime}$ for Class I and Class II concretes, respectively, Table 2 . The values of the modulus of elasticity values for light concrete are lower than those of Class II concretes ibid, while natural concretes were classified as Class I concretes.

Maximum unit deformations of light concrete were lower than those of natural concrete, falling within the range from 0.0025 through 0.0029 . Available works in technical literature up to date do not show results similar to the results obtained in this research. In our samples, the modulus of elasticity for natural concrete had a $210.75 \mathrm{E} * 10^{3} \mathrm{~kg} / \mathrm{cm}^{2}$ arithmetic mean, while light concrete had a $77.75 \mathrm{E} * 10^{3} \mathrm{~kg} / \mathrm{cm}^{2}$ arithmetic mean. Its sample standard deviations are: 45.69 $\mathrm{E} * 10^{3} \mathrm{~kg} / \mathrm{cm}^{2}$ and $16.99 \mathrm{E} * 10^{3} \mathrm{~kg} / \mathrm{cm}^{2}$ respectively, with almost identical variation coefficients: $18.77 \mathrm{E} * 10^{3} \mathrm{~kg} / \mathrm{cm}^{2}$ and $18.93 \mathrm{E} * 10^{3} \mathrm{~kg} / \mathrm{cm}^{2}$. Its kurtosis coefficient (indicator of its distribution degree of asymmetry) has a value closely related: $1.75 \mathrm{E} * 10^{3} \mathrm{~kg} / \mathrm{cm}^{2}$ for natural concrete and 1.44 $\mathrm{E} * 10^{3} \mathrm{~kg} / \mathrm{cm}^{2}$ for light concrete. Since its value is positive, its distribution is normal and leptokurtic, high, or elongated. A sample showed a value of $263.0 \mathrm{E} * 10^{3} \mathrm{~kg} / \mathrm{cm}^{2}$, close to standard values of concrete. The values of the modulus of elasticity are highly correlated to concrete in 0.972 and 0.971 , as well as to tensile stress at 28 days, 0.992 . Now, a value of the modulus of elasticity lower for light concrete than for natural concrete means lower stress in the same direction than unitary deformations.

\section{Concrete Mixtures}

There are some other important parameters to understand the mechanical behavior of the material, which were not calculated in this study, since some laboratory tests were not carried out. Such are: Poisson ratio, the highest tensile stress (the point where the curve of the material falls, corresponding to the highest load), and the fracture energy (important property of the material to be considered in numerically simulating the evolution of the damage within the material).

\section{Cement, Sand, PET, and Water Interaction}

Compound materials are structures in which two or more materials are combined to produce a new one, the properties of which may not be achieved by means of conventional methods. Compound materials are more frequently used in structural material where rigidity, strength, and low density are important factors at a relatively low cost. Cement fiber, sand, and PET are strong and rigid, but have low ductility. Water, plays two important roles: it acts as a medium for transferring binding and creates the interface between cement, water and sand, where there is a chemical reaction, although there is no reaction between these three elements and PET, but only a certain amount of adherence. PET substitutes gravel and reacts when subject to high temperatures.

\section{Multivariate Statistical Analysis of Tests}

In order to get an idea of the statistical-mathematical relationships existing in the tests carried out on the mixtures with natural and light concretes, multidimensional analyses were carried out on proportioning data, fresh volumetric weights, air contents and compression, tensile, and flexural strength of concretes, as well as on values of the modulus of elasticity of concretes. Its higher correlation is due to the tensile strength of Class I and II concretes in the tensile and flexural strength and modulus of elasticity, with a 0.992 correlation value. The one that is less correlated is Class II concrete, regarding flexural resistance with water and gravel/PET, with a 0.040 correlation value. The correlations circle, Figure 11, shows the first component. With $64.7 \%$ of data, the water/concrete ratio, opposed to concrete quantities used in Class I and II concretes of flexural strength tests at 14 days and tensile strength at 28 days. The second main 
component, with $29.7 \%$ of data, is the amount of sand used in proportioning of gravel/PET and its modulus of elasticity, opposed to the quantity of water used.

In order to taxonomize and describe the data under analysis, a hierarchical classification was chosen, which is a mathematical technique for such purpose. Mathematically, a classification of two nonempty subsets $\mathrm{A}$ and $\mathrm{B}$ of a set $I$ is a partition where the intersection of A and B is empty. The main purpose of the classification is to obtain a simple schematic representation, as a dendrogram, of a rectangular data table. There is another, simpler, purpose, which is to distribute the sample in groups of homogeneous observations, where every group is different from the others, for such purpose, there are various addition methods, in accordance with the data to be classified. Hierarchy is represented with a tree diagram (or hierarchical tree, if the classification is of this type) [29]. In this case, an ascending hierarchical classification was carried out, based on a Euclidean distance with a minimal aggregation criterion based on the values of the main components, Figure 12. Such has been split in 7 hierarchical branches and its interpretation yields that water, concrete, the water/concrete ratio, the air content, and sand are independent from any process to produce concrete/PET. The sixth hierarchical branch adds the modulus of elasticity with the volumetric weight and then the gravel/PET ratio. The last hierarchical branch, the largest, adds Classes I and II concretes in tensile and flexural stress, with the water/concrete ratio directly related to its annealing.

\section{Conclusions}

Recycling PET to manufacture coarse aggregates and substitute natural aggregates should begin to spread as soon as possible, as stony material banks are scarce, and access to quarries is becoming more and more complicated.

The research work revealed that PET aggregate produces good quality mixtures with lower volumetric weight and mechanical behavior similar to that of natural concrete with adequate granulometry. The water/cement $(W / C)$ ratio is lower for light concretes than for natural concretes. Light concretes may be used as Class II concrete, which renders them concretes with high quality for various applications such as use in light slabs for homes within hot areas, due to their lower weight, since there is no comparison between various heat levels in concrete with PET. Cement consumption is higher for light concretes with PET than for natural concretes.

Most shrinkages are within tolerable limits $( \pm 2.5 \mathrm{~cm})$ established in Section 6.1.2 of ASTM C 94 [21] Standards. Only CN-300 mixture was close to the limit allowed.

Regarding stress and flexural strength, it was found that when $300 \mathrm{~kg} / \mathrm{cm}^{3}$ of cement, or more, was used, the $f_{t} /\left(f_{c}\right)^{1 / 2}$ and $M_{R} /\left(f_{c}\right)^{1 / 2}$ relationships were lower for light concrete, which may be due to the fact that at low $W / C$ ratios, the behavior of the coarse aggregate and high $W / C$ ratio prevails, while at high $W / C$ ratios, the behavior of paste prevails. This means that the best application of PET aggregate is in low use of cement, up to $300 \mathrm{~kg} / \mathrm{m}^{3}$, since it may be expensive to use it for higher volumes.

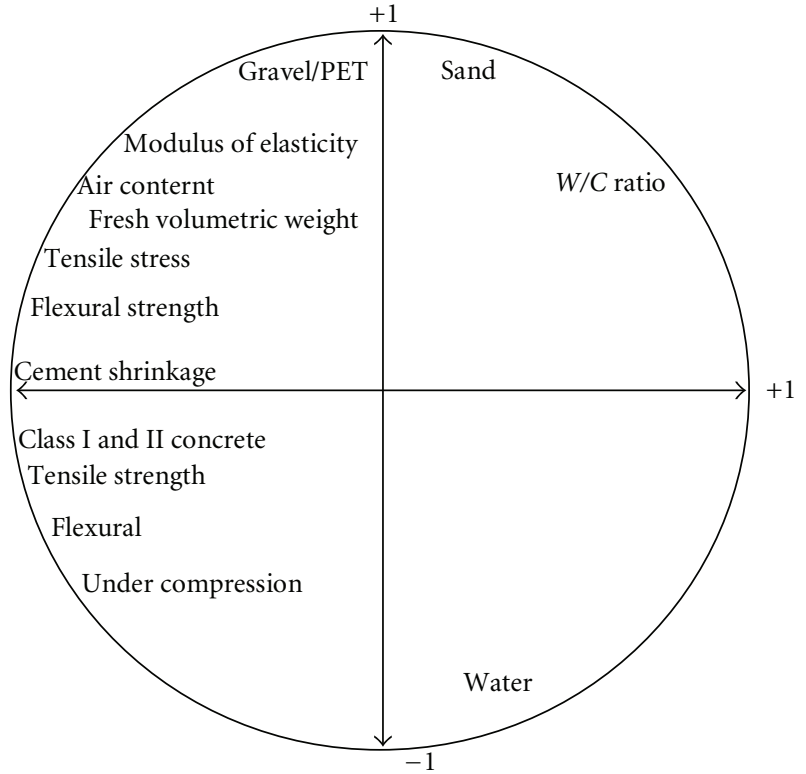

FIGURE 11: 1-2 correlations circle. First two components with 94.4 $\%$ of data.

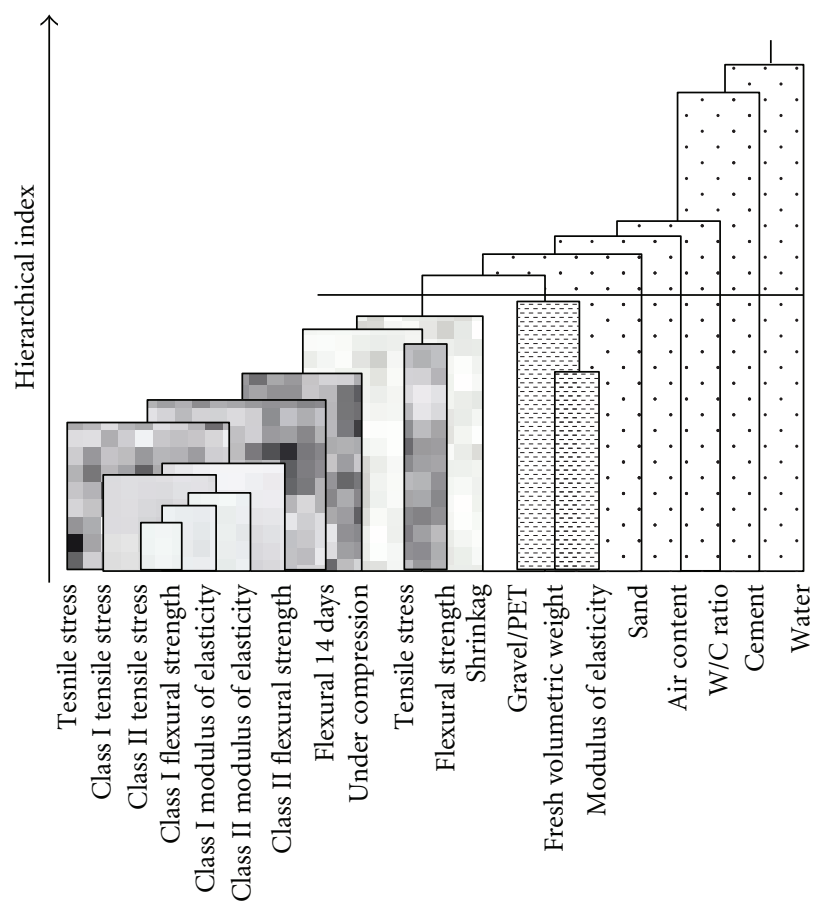

FIgURE 12: Hierarchical tree of light concretewith PET aggregate production.

The modules of elasticity of light concrete are lower than those of natural concrete, and deformations of light concrete are lower for light concrete than for natural concrete.

From the point of view of a statistical analysis, it has been found that there is a higher consistency for light concrete mixtures than for natural concrete mixtures, this have been confirmed through variation coefficients, since such are 
lower for light concrete. Values distribution is normal leptokurtic elongated. The values of the modulus of elasticity are highly correlated to concrete and tensile stress at 28 days. Now, a value of the modulus of elasticity lower for light concrete than for natural concrete means that light concrete has a lower stress in the same direction as unitary deformations. Hierarchical classification provides a dendrogram with 7 hierarchical branches, and its interpretation yields that water, concrete, the water/concrete ratio, the air content, and sand are independent of any process to produce concrete/PET. The sixth hierarchical branch adds the modulus of elasticity with the volumetric weight and then the gravel/PET ratio. The last hierarchical branch, the largest, adds Classes I and II concretes in tensile and flexural stress, with the water/concrete ratio directly related to its annealing.

\section{Acknowledgments}

This research was carried out with the support of the Academic Architectural Engineering Division of the Universidad Juárez Autónoma de Tabasco, México to carry out laboratory experiments on material mechanics and the Research Project SIP IPN: 20100674.

\section{References}

[1] L. Alesmar, N. Rendón, and M. E. Korody, "Diseños de mezcla de tereftalato de polietileno (PET)-Cemento," Revista de la Facultad de Ingeniería de la U.C.V, vol. 23, no. 1, pp. 77-86.

[2] Y. W. Choi, D. J. Moon, J. S. Chung, and S. K. Cho, "Effects of waste PET bottles aggregate on the properties of concrete," Cement and Concrete Research, vol. 35, no. 4, pp. 776-781, 2005.

[3] O. Y. Marzouk, R. M. Dheilly, and M. Queneudec, "Valorization of post-consumer waste plastic in cementitious concrete composites," Waste Management, vol. 27, no. 2, pp. 310-318, 2007.

[4] F. Mahdi, H. Abbas, and A. A. Khan, "Strength characteristic of polymer mortar and concrete using different compositions of resins derived from post-consumer PET bottles," Construction and Building Materials, vol. 24, no. 1, pp. 25-36, 2010.

[5] C. Albano, N. Camacho, M. Hernández, A. Matheus, and A. Gutiérrez, "Influence of content and particle size of waste pet bottles on concrete behavior at different w/c ratios," Waste Management, vol. 29, no. 10, pp. 2707-2716, 2009.

[6] F. Mahdi, H. Abbas, and A. A. Khan, "Strength characteristics of polymer mortar and concrete using different compositions of resins derived from post-consumer PET bottles," Construction and Building Materials, vol. 24, no. 1, pp. 25-36, 2010.

[7] M. Frigione, "Recycling of PET bottles as fine aggregate in concrete," Waste Management, vol. 30, no. 6, pp. 1101-1106, 2010.

[8] S. Akçaözoğlu, C. D. Atiş, and K. Akçaözoğlu, "An investigation on the use of shredded waste PET bottles as aggregate in lightweight concrete," Waste Management, vol. 30, no. 2, pp. 285-290, 2010.

[9] 2010, http://www.packaging.enfasis.com/contenidos/home. .html

[10] C. Cortinas de Nava and S. Vega Gleason, Residuos Peligrosos en el Mundo y en México, Serie Monografías, no. 3, SEDESOL, Instituto Nacional de Ecología, Coyoacán, Mexico, 1993.
[11] J. A. Carega, Manejo y Reciclaje de los Residuos de Envases y Embalajes, Serie Monografías, no. 4, SEDESOL, Instituto Nacional de Ecología, Coyoacán, Mexico, 1993.

[12] ASTM C-33-90, Standard specification for concrete aggregates, 1990.

[13] ASTM C-125-07, Standard terminology relating to concrete and concrete aggregates, 2007.

[14] Norme AFNOR P-18301 and AFNOR GROUP, Opérateur national et international au service de la performance et du développement durable des entreprises et de la société civile, France, 2008.

[15] ASTM C-566-89, Standard method for total moisture content of aggregate by drying, 1989.

[16] ASTM C-127-88, Standard test method for specific gravity and absorption of coarse aggregate, 1988.

[17] ASTM C-128-88, Standard test method for specific gravity and absorption of fine aggregate, 1988.

[18] S. H. Kosmatka and W. C. Panarese, Diseño y control de mezclas de concreto, IMCyC, Mexico City, Mexico, 1992.

[19] ACI-211.1-89, Standard practice for selecting proportions normal, heavy weight, and mass concrete, 1989.

[20] CEMEX Unidad concreto Cemex, Biblioteca del CIDETEC, Cemex, Mexico City, Mexico, 1996.

[21] ASTM C-94-90, Standard specification ready mixed concrete, 1990.

[22] Instructivo para efectuar pruebas en agregados y concreto hidráulico, vol. 3, Secretaría de Asentamientos Humanos y Obras Públicas, Mexico, 1991.

[23] ASTM C-138-81, Standard test method for unit weigth, yeild, and air content (gravimetric) of concrete, 1981.

[24] ASTM C-231-91, Standard test method for air content fleshly mixed concrete by the pressure method, 1991.

[25] ASTM C-39, Standard test method for compressive strength of cylindrical concrete specimens, 1990.

[26] ASTM C-496-90, Standard test method for splitting tensile strength of concrete specimens, 1990.

[27] ASTM C-78-84, Standard test method for flexural strength of concrete (using simple beam with third point loading), 1984.

[28] ASTM C-469-87a, Standard test method for static modulus of elasticity and poisson's ratio of concrete in compression, 1987.

[29] F. Casanova-del-Angel, Análisis Multidimensional de Datos, Logiciels, Mexico, 2001. 

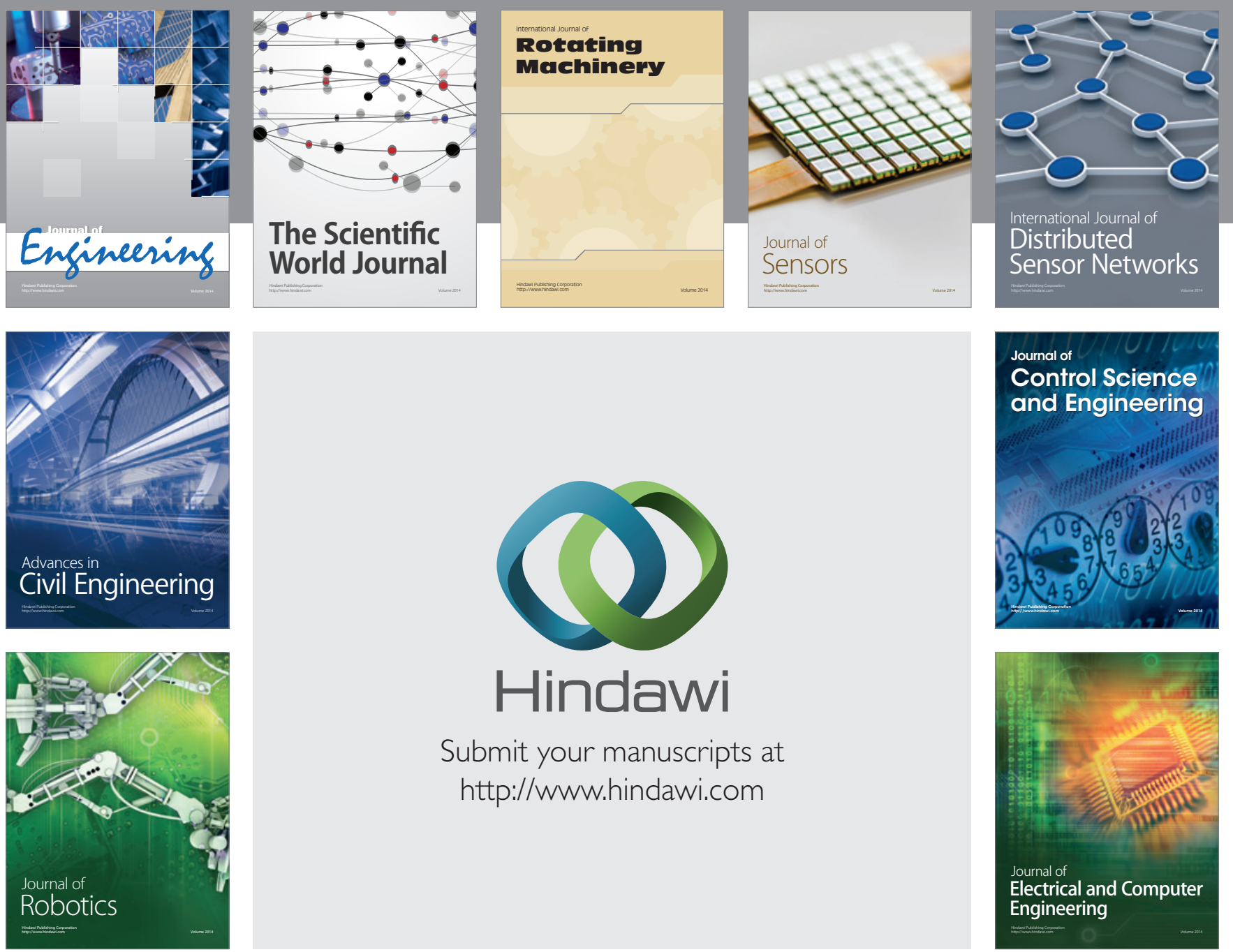

Submit your manuscripts at

http://www.hindawi.com
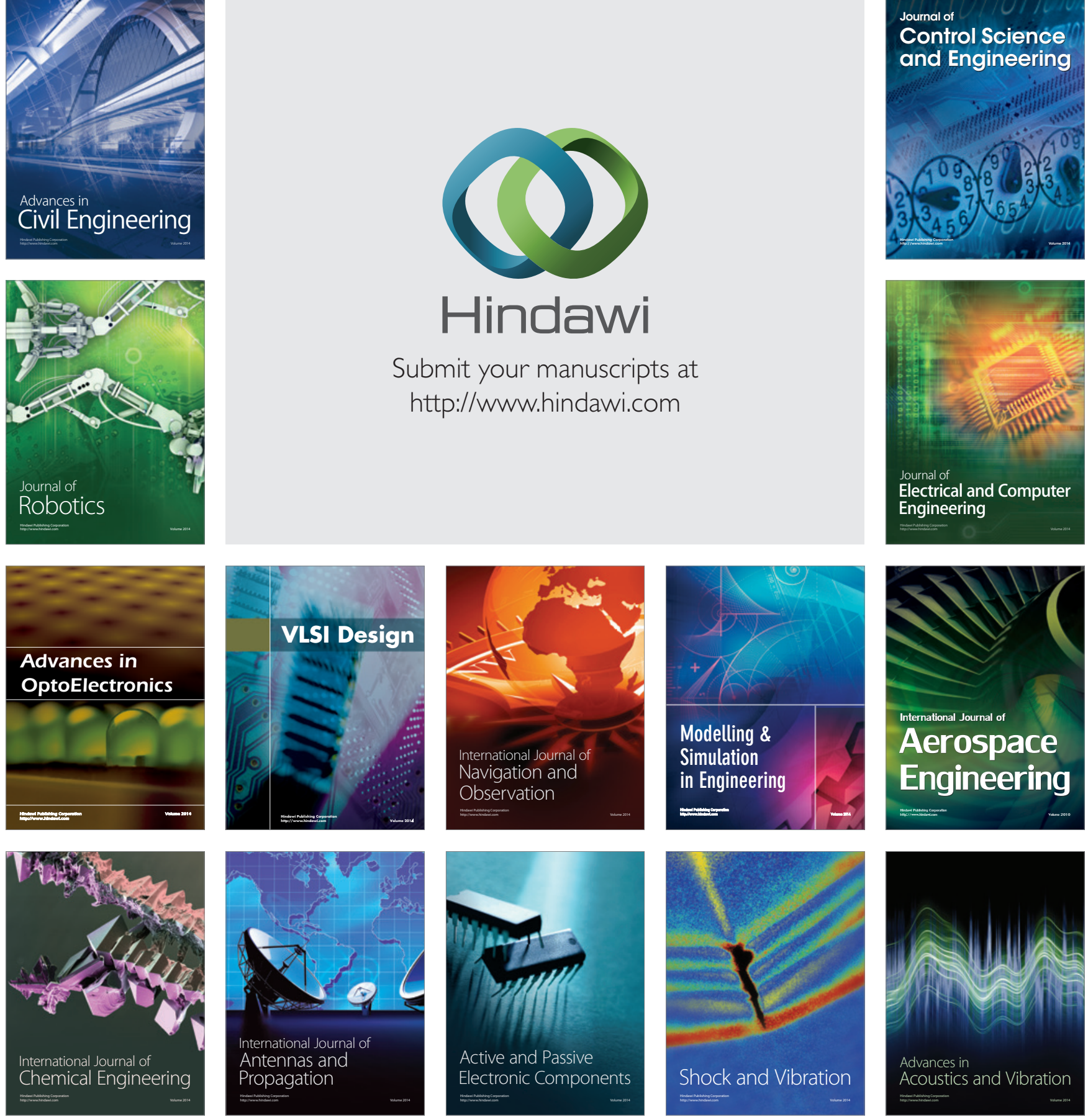